\title{
Prof. Planck and the Principle of Causality in Physics*
}

\section{By Dr. Alran Ferguson}

$\mathrm{T}$ E Guthrie lecturers before the Physical Society have in the past covered a wide range of knowledge in physical science, but they have very definitely concerned themselves with concrete prob. lems. Atomic nuclei, electrodeless discharges, the properties of the elements under high pressures, the scattering of $\mathrm{X}$-rays in gases, positive rays -these are typical of the subjects which have been discussed and illuminated by distinguished lecturers in past years. It has been left to Prof. Max Planck to treat with wide scholarship and philosophic insight one of the most difficult of the problems known to the thought of any age-that of the meaning and validity of the concept of causality.

It was a singularly happy chance which dictated the choice of this topic to Prof. Planck, for he, as much as any other living thinker, has forced upon the minds of the rank and file of physicists the necessity for some measure, at least, of metaphysical knowledge, and has roused us from that attitude of crude realism typified by Johnson, who, required by the insatiably curious Boswell (on Harwich beach, of all places) to criticise Berkeley's idealism, "answered, striking his foot with mighty force against a large stone till he rebounded from it, "I refute it thus" ". Nor must it be imagined that this simple attitude was a prerogative of the privates in our army. The habit of mind was to be found in very high places. Thus, turning to a lecture on the wave theory of light by the late Lord Kelvin, we find therein the very definite and uncompromising statement: "You can imagine particles of something, the thing whose motion constitutes light. This thing we call the luminifer. ous ether. That is the only substance we are confident of in dynamies. One thing we are sure of, and that is the reality and substantiality of the luminiferous ether." Less than fifty years have passed since these words were spoken, less than twenty-five since the speaker died; and the onset of the revolutionary change which has come over our physical thinking is marked by a paper published during Lord Kelvin's lifetime under the name of Max Planck in the last year of the nineteenth century.

It is impossible, and undesirable in the scope of a short article, to attempt an exhaustive review of the development of the concept of causality, but it is not without interest and bearing on present-day thought to consider briefly the development of the concept since the age of Newton. Locke, Newton's elder contemporary, states a clear and simple view, which, however, scarcely touches the fringe of the problem, when he says: "Thus, finding that in that substance which we call wax, fluidity, which is a simple idea that was not in it before, is constantly produced by the application of a certain

* Seventeenth Guthrie Lecture before the Physical Society, delivered by Prof. Max Planck on June 17. degree of heat, we call the simple idea of heat in relation to fluidity in wax the cause of it, and fluidity the effect. . . . So that whatever is considered by us to conduce or operate to the producing any particular simple idea, whether substance or mode, which did not before exist, hath thereby in our minds the relation of a cause and so is dominated by us." The notion of power in this definition of cause is particularly evident.

The mind of Newton, as Prof. Brodetsky has recently remarked, was dominated by the principle of causality, and he was ever searching for a physical picture which should represent the results of his investigations. This is very true; but it is to be remembered that in this, as in so many other matters, Newton displayed a philosophic breadth of view which was well in advance of the doctrines of his day. He makes, for example, a physical picture of matter as formed in " solid, massy, hard, impenetrable, moveable particles", and assumes that they have not only a vis inertiae, but are moved by certain active principles, such as gravity. These principles are to be considered "not as occult qualities... but as general Laws of Nature... their Truth appearing to us by Phænomena. . . To tell us that every Species of Things is endowed with an occult specifick Quality by which it acts and produces manifest effects, is to tell us nothing; but to derive two or three Principles of Motion from Phænomena and afterwards to tell us how the Properties and Actions of all corporeal Things follow from these manifest Principles would be a very great step in Philosophy, though the Causes of those Principles were not yet discovered; and therefore I scruple not to propose the Principles of Motion above mentioned, they being of very general extent, and leave their Causes to be found out." Evidently despite, or perhaps it would be better to say, along with his physical picture, Newton takes the view that we have made an important step when we have subsumed a number of perceptual facts under one general formula.

Although he may be indebted to Glanvill and other earlier writers, it is to Hume that we owe the first clearly ordered statement of the experientialist doctrine of causation. Such a generalisation, applied to a falling body, as "the earth attracts the stone", is explained as a generalisation from thousands of such observations. "Adam ... could not have inferred from the fluidity and transparency of water that it would suffocate him, or from the light and warmth of fire that it would consume him. No object ever discovers by the qualities which appear to the senses, either the causes which produced it or the effects which will arise from it; nor can our reason, unassisted by experience, ever draw any inference concerning real existence and matter of fact." So, basing his argument entirely on experience, Hume defines a cause as "an object, followed by another, and 
where all the objects similar to the first are followed by objects similar to the second. Or, in other words; where, if the first object had not been, the second had never existed."

We may note here that the experientialist position was, in the nineteenth century, further developed by Mill, who states that the law of causation "is but the familiar truth that invariability of succession is found by observation to ob. tain between every fact in nature and some other fact which has preceded it, independently of all considerations respecting the ultimate mode of production of phenomena, and of every other question regarding the nature of things in themselves ". Mill, moreover, meets the objection urged by Reid that on such a doctrine of succession, day must be the cause of night and vice versa, by pointing out that invariable sequence does not necessarily involve the notion of causation. To involve this last-named notion, the sequence must be unconditional as well as invariable. The daynight sequence obviously does not conform to this test, inasmuch as it is conditioned by the behaviour of our luminary, the sun. "We may define, therefore, the cause of a phenomenon to be the antecedent, or the concurrence of antecedents on which it is invariably and unconditionally consequent."

Kant's discussion of causality, wherein he takes the position that we could never make such a generalisation as " the earth attracts the stone" unless we had knowledge $a$ priori and independent of experience that each event in our perceptions has its cause, has great importance in the history of philosophic thought ; here we may pass it without comment, inasmuch as Kant's views have not played any decisive part in the development of scientific theory in this or in the last century.

Nineteenth century science, indeed, and specially nineteenth century English science, was in many ways, naïvely realistic; models played a large part in its development, and, while a model may serve a very useful end if it is thrown on one side, as Maxwell discarded his models, when it has fulfilled its purpose, there are, as we have already seen, serious dangers ahead when the model is elevated to the dignity of a 'reality'. None the less, a movement was on foot, owing much to Mach in Germany, and to Pearson in England, which, had its followers been greater in number, would have eased the path of many a physicist who, harassed by the conflicting claims of determinists and indeterminists, exclaims, "A plague on all your houses-let us go and make experiments". Kirchhoff had the root of the matter when he wrote, "Die Mechanik ist die Wissenschaft von der Bewegung; als ihre Aufgabe bezeichnen wir : die in der Natur vor sich gehenden Bewegung vollständig und auf die einfachste Weise zu beschreiben ".

We live in a world of perceptions; sense impressions come and go; and we find that we can regularise these impressions if we devise a conceptual world of atoms and molecules, from which we build up particles and molar masses the behaviour of which corresponds to the routine of our sense impressions. Given a frame of reference, we can formulate laws of motion for two isolated particles in a conceptual world, which may be summed up in the statement that whatever the relative positions of the particles, the ratio of their accelerations is always found to be constant; we define this ratio as the inverse mass-ratio of the particles; and since in virtue of this we have the relation that

mass of $A \times$ acceleration of $A=$ mass of $B \times$ acceleration of $B$,

we agree to give the name force to this product and obtain the law that action and reaction are equal and opposite. Moreover, on the basis of such definitions, we can build up a structure of bodies in the conceptual world the motions of which, predictable under the descriptive laws formulated, will agree with the routine of our world of perceptions. We have, in fact, explained certain phenomena.

Obviously, such a scheme of explanation puts out of court at once all those arguments concerning the contrast between dead mechanisms and living wills so dear to the Victorian controversialist. It is purely a matter of the relative complexity of the descriptive laws ; one set of astronomical perceptions are subsumed under laws of comparative simplicity ; another set of perceptions in the realm of biology requires a more complex scheme for its description. It may or may not be that in the future the two sets of perceptions may be described in terms of a common formula, but the difference, as Prof. Pearson says, is rather " quantitative than qualitative; the descriptions of mechanics are simpler and more general than those of biology". Evidently in such a description the idea of cause as involving power is out of place, and the definition in terms of invariable (and unconditional) succession as developed by Mill is also here appropriate.

Such, then, were the views concerning causality and scientific explanation which had been developed when the twentieth century and the quantum theory came into being. How have they been modified by the discoveries of the last generation?

This is the question which Prof. Planck sets out to answer, and, alive to the fact that most controversies, in the absence of exact definitions, tend to degenerate into logomachies, he seeks for an exact definition of the causal condition and finds it in the statement that an event is causally conditioned if it can be predicted with certainty. Prof. Planck goes on to remark that this statement has to be taken to mean that the possibility of making a correct prediction forms an infallible criterion for the agency of a causal connexion, but not that the two mean one and the same thing. In daytime, he remarks, we can predict with certainty the advent of night; but day is not the cause of night.

Prof. Planck then points out that, nevertheless, we assume a causal connexion in cases, for example, weather forecasting, where a correct prediction may not be possible, though in a case such as the last named the unreliability may be determined by the complicated nature of the object considered. In this part of his address, the compression of the

No. 3271, VoL. 130] 
thought has led to obscurity which may give rise to misinterpretation. Any event which may be predicted with certainty is in the universe of causally conditioned events. This latter universe, we note, may be coterminous with or greater than that of predictable events. If we interpret Prof. Planck rightly, the statement has to be taken at its face value and gives no indication of the sequence of conditioned events-no indication, that is, of the two events which stand to each other in the relation of cause and effect. Thus, day is an event which may be correctly predicted in the night-time; all that we assert, then, is that day is a causally conditioned event, not that there is, or is not, any causal connexion between day and night. This definition, in its condensed form, is so different from those advanced by other philosophers, who are concerned, in a definition of cause and effect, with an invariable sequence of events, that it should be carefully examined in the light of the arguments of Hume (" Enquiry concerning Human Understanding ", Section vii.) and of Mill ("Logic", Book iii. Chap. v.).

Taking the phrase as it stands, we find that, in the realm of quantitative physical events, however simple the event, however delicate our instruments, we cannot calculate accurately in advance the result of our measurement - that is, in no single instance can we predict infallibly a physical event. Hence the dilemma-if we adhere to our definition of causality-there is no physical event which is causally conditioned, and we become indeterminists, asserting that not one of the laws of Nature is absolutely valid, not even the law of gravitation ; the appearance of validity is illusory, and the laws are laws of probability. If, rejecting this indeterminist picture, we endeavour to retain the concept of causality, we find it necessary to introduce some modification into our fundamental definition of causally conditioned events; and that modification is made by transferring the definition to a conceptual world in which exact measurements may be made and events correctly predicted. The mechanism of this conceptual world, and the process of connecting two events in the world of perception by the use of the conceptual picture, fully agree with that previously outlined, and it would seem that the adoption of the theories of Mach and of Pearson would enable us, even while recognising that an unavoidable uncertainty is attendant on the prediction of an event in the perceptual world, to retain the concepts of causality as accurately valid in our conceptual picture, the relation between perceptual and conceptual events being subject to a slight inaccuracy in the process of translation from the conceptual world to the world of sense impressions.

More than this; in the region of gas-kinetic theory - a domain which, more than any other, might be regarded as a happy hunting ground for the indeterminist seeking a description based entirely, even down to the collisions of individual molecules, on statistical laws-the principle of causality won one of its greatest triumphs: for it has been found possible to build up in the con- ceptual world a strictly causal mechanism, the conclusions drawn therefrom, on transference to the world of sense impression, giving a remarkably accurate picture even of those irregular fluctuations which are the chief hope of the indeterminists.

How is this state of affairs modified by the introduction into our concepts of the quantum of action and of Heisenberg's uncertainty principle, which states that the product of the uncertainties of, for example, the position and momentum of a particle is constant, so that any gain in accuracy of the one determination is balanced by a corresponding loss in accuracy of the other? Here again a new conceptual world of quantum physics may be framed in which a strict determinism reigns, and the problem of transfer between this world and the world of sense impressions is philosophically identical with that of our classical problem. In actual fact, it is more difficult; for the symbols of our classical conceptual world bore some resemblance to the routine of our perceptions-our mechanism of billiard ball atoms and the like was based on our everyday sense impressions. The wave function is not so easily interpreted in terms of the world of sense. It does not refer to ordinary space; it does not give the values of the coordinates as functions of the time, but gives the probability that the co-ordinates will possess given values at a definite time-a position which gives an obvious loophole for the indeterminist.

So we find a continual sway between determinism and indeterminism. For the indeterminist the statement that the wave function is a probability function is sufficient and satisfactory; laws such as the law of gravitation present to him unsolved problems to which he must find exceptions, calculating the probability that the force will diverge from the inverse square law by a certain definite amount. For the determinist, the inverse square law is a law of Nature, and he puts up with the probability function only as a pis aller, to be resolved later into relations subject to law.

Prof. Planck's test of the relative value of the two positions is a pragmatic one-there is nothing for it, he says, but to adopt one of the two points of view and to see whether we obtain valuable or useless results. At the moment, in his opinion, the indeterminists are in the majority, but, while he holds the balance with remarkable fairness, it is not too much to say that his sympathies are with the advocates of causality. Nowhere does he show this sympathy more deeply than in a daring final speculation. After reverting to the fundamental propositions that an event is causally conditioned if it can be infallibly predicted and that in no single case is it possible to predict an event accurately, he points out that we retained the principle of causality by modifying the event-by referring this to a conceptual world.

Since, however, all predictions imply a predicter - since the certainty of a prediction depends in a high degree on that predicter--suppose we modify the subject of prediction, the predicting mind, and assume anidealmind capable of a pprehending in their minutest details all the physical occurrences of the 
universe: we have here a ' conceptual' mind which would predict accurately all physical events. What the good Bishop Berkeley would think of this, we do not presume to say; the speculation is fascinating, even though, as Prof. Planck remarks, in order to accomplish such a notion we must subject ourselves to a severe restriction-we must forgo making the ideal mind the subject of a scientific investigation.

Although Prof. Planck's conviction, that the law of causality is, in spite of the difficulty of a general proof or disproof, a valuable sign-post to guide us through the tangle of perceptions in which we live, shows the direction of his own sympathies, he does not suggest that the answer he had given to the question originally raised is more than a tentative one. But, tentative though the answer may be, the question has provoked a brilliant, thoughtful, and stimulating address, which will live long in the memories of those whose privilege it was to be present at the Guthrie Lecture for 1932.

\section{Jérôme de Lalande, I732-I807}

$\mathrm{T}$ HE absorbing interest felt by the general reader in the outstanding men and events of the French Revolutionary period is to a great extent experienced by the student of the lives and characters of the French men of science who laboured during that remarkable time. During the latter part of the eighteenth century Paris was the centre of amazing intellectual activities, which even the vicissitudes of the most perilous days could not quench, and which, after the worst dangers were past, were resumed with increased zest. Especially was this the case with scientific studies and instruction. Old institutions of which the very life had been threatened were reorganised, and beside them sprang into existence others destined quickly to rival in renown any that had gone before. To one or other of the many institutions belonged most of the eminent men of science of France, among whom were Laplace, Lagrange, Delambre, Monge, Haüy, Berthollet, Chaptal, Coulomb, Lacépède, Lamarck, and last but not least, the astronomer Lalande, the bicentenary of whose birth occurs this month.

Joseph Jérôme Lefrançais de Lalande was born at Bourg-en-Bresse in the department of Ain, on July 11, 1732, and died in Paris on April 4, 1807, in his seventy-fifth year. Never in need of labouring for his daily bread, his life was yet one of unceasing effort, and from the time when as a boy he came under the Jesuit schoolmasters at Lyons until old age came upon him, his industry was remarkable. It is true that as an astronomer he has never been reckoned in the first rank as a discoverer or an investigator, but as an exponent of astronomy and a populariser of science he has had few equals. His industry is attested by the list of more than two hundred memoirs and books he wrote, but much of his influence on the progress of astronomy was due to the lectures he gave during the forty-six years he held the chair of astronomy at the Collège de France and to his encouragement of students. Though no great discovery stands to his credit, by his writings and lectures he gained for his favourite science a popularity previously unknown, and it is for that he is chiefly remembered.

Lalande's interest in astronomy is said to have been aroused by seeing a comet and watching an eclipse, and to have been further stimulated by reading Fontenelle's "Plurality of Worlds". It was, however, his contact with Delisle and Lemonnier which led him to abandon the law courts for the observatory, and it was through Lemonnier that as a youth of nineteen years of age he was sent to Berlin to make observations simultaneously with those being made at the Cape by Lacaille for determining the parallax of the moon. From the court of Frederick the Great and the society of Euler, Lalande returned to Paris and at the age of twentyone was given a place as 'adjoint-astronome' in the Paris Academy of Science. He became an 'associé ' in 1758 and a 'pensionnaire' in 1772 .

With the account of his work at Berlin began the long series of memoirs referred to. A few years later, for Clairaut he made a mass of calculations in connexion with the predicted return of Halley's comet; in 1761 he succeeded Maraldi as editor of the "Connaissance des Temps"; in 1762 he succeeded to Delisle's chair at the Collège de France, and in 1764 he published the first part of his "Traité d'astronomie ". Other parts followed in 1771 and 1792. "This compilation", wrote Thomas Young, "far excelled in utility all former works of the kind, and will always be considered as exhibiting the most perfect picture of the science such as it existed from 1760 to 1790 with all the details of practice and computation." Lemonnier called Lalande's work "the great newspaper of astronomy". Another notable work of Lalande was his "Histoire céleste", published in 1801, giving the places of 47,390 stars, the observations for which were made chiefly by his nephew Michel Lalande and D'Agelet, both of whom he had instructed.

The character of Lalande was no less interesting than his work. It was once said of him that he was as anxious to direct attention to himself as an individual as to astronomy as a science. His love of flattery and publicity was undeniable; but he possessed many admirable traits. Generous to a fault, he encouraged and provided for many young and needy students, and during the Revolution his courage led him to protect others at his own risk. He visited England in 1788, conversed with George III., crawled through Herschel's great telescope at Slough, and it was due to him that Herschel's newly discovered planet, Uranus, was for a time called after its famous discoverer. Living abstemiously himself, he placed his fortune at the disposal of others, and towards the end of his life founded the Lalande medal, which became the 'blue ribbon' of the astronomical world. Quite early in his career, in 1763 , he was made a foreign member of the Royal Society, while the esteem in which his memory is still held in France was shown by the inauguration in 1909 of a monument to him at his birthplace, Bourg-en-Bresse.

No. 3271, Vor. 130] 